\title{
A AUSÊNCIA DA PADRONIZAÇÃO DE MEDIDAS NO VESTUÁRIO INFANTIL
}

\author{
Gisely Andressa Pires, mestranda do PPGDesign - UNESP \\ giselypires@utfpr.edu.br \\ Tamissa Juliana Barreto Berton, mestranda do PPGDesign - UNESP \\ tamissa@utfpr.edu.br \\ Marizilda dos Santos Menezes, docente do PPGDesign - UNESP \\ zilmenezes@uol.com.br \\ Celso Tetsuro Suono, docente UTFPR \\ suono@utfpr.edu.br
}

\begin{abstract}
Resumo: Na tentativa de criar produtos cada vez mais atraentes, a indústria do vestuário infantil busca inovar tanto em aspectos de design como conforto e qualidade. No entanto encontra-se uma falta de padronização das medidas nas roupas infantis. Considerado no mercado como um dos segmentos com crescimento acelerado, a indústria do vestuário infantil está deixando a desejar no desenvolvimento e estrutura da modelagem da roupa. Assim encontramos peças com diferenças grandes nas medidas do vestuário de um mesmo tamanho, o que dificulta a compra para o consumidor. Pensando em uma forma de padronizar as medidas a ABNT- Associação Brasileira de Normas e Técnicas colocou em vigor a NBR 15800, estabelecendo parâmetros com referenciais de medidas do corpo infantil para auxiliar as indústrias na padronização de medidas.
\end{abstract}

Palavras-chave: padronização, modelagem, medidas, infantil

Abstract: In trying to create increasingly attractive products, the children's clothing industry seeks to innovate in both design aspects such as comfort and quality. However there is a lack of standardized measures in children's clothing. Considered as one of the market segments with rapid growth, the children's clothing industry is found wanting in the development and structure of modeling the clothes. Thus we find pieces with large differences in the measurements of garments of the same size, making it difficult to buy for the consumer. Thinking of a way to standardize the measures to ABNT-Brazilian Association of Technical Standards and put into force the NBR 15800, establishing parameters with reference to 
measures of the child's body to assist the industry in standardizing measures.

Palavras-chave: standardization, modeling, measurements, kids

\section{INTRODUÇÃO}

A indústria de confecção do vestuário concentra muitos de seus produtos no segmento infantil, um mercado com grande crescimento em todo o mundo. $\mathrm{Na}$ tentativa de atrair cada vez mais esse público, que atualmente tem uma voz ativa na hora do consumo, empresas buscam inovar para crescer nesse mercado promissor. Porém quando diz respeito a roupas do vestuário, as empresas parecem se esquecer de que as crianças necessitam de uma estrutura de modelagem diferenciada. Produtos voltados para elas precisam ser bem projetados, pois as mesmas possuem características físicas diferentes dos adultos.

Diante disso é necessário que as empresas de confeç̧ão destinadas a esse público tenham o conhecimento da antropometria, ciência das medidas humanas, que serve de auxílio para construção da modelagem de roupa. Pensando nisso a ABNTAssociação Brasileira de Normas e Técnicas, colocou em vigor a NBR 15800:2009, sugerindo 24 medidas do corpo humano de 0 a 14 anos, para auxiliar as empresas em uma padronização de medidas. As mesmas não são obrigatórias, servem somente de auxilio para confecção do vestuário infantil. Desta forma o presente artigo buscou verificar, com base nas medidas sugeridas da NBR 15800:2009, sobre como está a padronização das roupas infantis no mercado, verificando se existe atualmente uma preocupação das empresas em relação a este tema, analisando assim as medidas de de marcas de roupa para bebê de empresas distintas.

\section{MERCADO DE MODA INFANTIL}

A sociedade estabelece a infância como um período de preparação para a vida adulta, e por muito tempo crianças de até 7 anos não eram considerados como sujeitos na sociedade. "Desde os primórdios a palavra infância carrega consigo sentimento de incapacidade, da incompletude perante os mais experientes, conferindo-lhes uma posição subalterna diante dos membros adultos..." (MARSSARI, 2010, pg. 34). Nessas condições as roupas confeccionadas para elas seguiam o vestuário adulto, sem existir uma produção de roupas específica para esse público. Para Gonçalves \& Beirão Filho (2007) as roupas infantis estabelecia-se apenas a partir de uma redução das proporções das roupas adultas.

Em contrapartida, o Século XX foi marcado pelo crescente interesse na criança, gerando um movimento sócio-político voltado para a sua assistência e proteção. Além disso, o mercado passou a percebê-las como consumidoras, pois as mesmas desenvolveram interesses e conhecimentos maiores pelos produtos consumidos. Com essa mudança houve uma necessidade de adaptação do vestuário infantil, desta forma as peças criadas e confeccionadas atualmente apresentam características para que as crianças sintam-se atraídas por elas. 
A população brasileira cresceu $42 \%$ desde 1980 , segundo dados do IBGE. No mesmo período, o crescimento infantil foi de apenas $8 \%$. Os principais motivos para essa queda nas taxas de natalidade estão nas mudanças ocorridas na sociedade brasileira nos últimos anos, em especial, em relação a mudanças no comportamento feminino, com mulheres mais presentes no mercado de trabalho. Neste contexto o que ocorre é que, à medida que a taxa de natalidade cai, a importância dos filhos aumenta, bem como o seu papel dentro da família. Com voz ativa, estas crianças são cada vez mais influenciadoras dentro dos lares e só consomem o que lhes agrada, sem imposições.

Para a Associação Brasileira da Indústria Têxtil (ABIT), o segmento infantil já representa $15 \%$ do mercado de moda, e movimenta US\$ 4,5 bilhões anuais. As despesas para famílias brasileiras com crianças duplicaram nos últimos cinco anos (DAUJOTAS, 2011). Com todo esse crescimento de consumo, as indústrias de confecção infantil buscam se especializar cada vez mais, atualmente grandes marcas do segmento adulto investem no segmento infantil. Podemos encontrar marcas internacionais como Armani, Stella McCartney, Gucci e no Brasil, estilistas como Adriana Barra e Ronaldo Fraga que também desenvolvem desde 2003 peças exclusivas para crianças.

Apesar do mercado para esse público estar em alta, é necessário tomar alguns cuidados na produção de peças para os mesmos. Crianças exigem produtos diferenciados dos adultos, principalmente em sua estrutura física, não sendo possível fazer somente uma redução da modelagem adulta, pois suas proporções físicas são diferentes. Sendo assim, a medida da roupa caracteriza-se como um dos principais elementos a serem analisados na confecção. Desta forma, dentre as diversas propostas para a regulamentação e padronização na indústria de vestuário infantil, foi lançada em 2009 a NBR 15800:2009 que orienta os referenciais de medidas para o desenvolvimento das roupas infantis. Proposta pela ABNT como forma de garantir padrões unificados, a norma busca favorecer a compra e venda de produtos desse nicho de mercado, facilitando o crescimento do volume de vendas comercializado pela Internet e exportação dos produtos.

\subsection{Modelagem Infantil}

O design de moda busca atender e suprir desejos e necessidades dos consumidores, sendo necessário desenvolver com frequências novos produtos. Nesse processo o modelista é o profissional que viabiliza através dos moldes a materialização do produto elaborado pelo designer de moda. Deste ponto de vista, a modelagem é o processo responsável pela viabilização de um desenho/criação para a produção industrial.

A modelagem, segundo Araújo (1996) consiste na "arte de confecção de moldes a partir de um modelo pré-estabelecido". Cabe ao modelista, por sua imaginação e capacidade de observação, ser capaz de adaptar, transformar e criar moldes, dentro daquilo que é o mais importante: a base do corpo. A modelagem tem como objetivo, adaptar a coleção à produção, por meio do desenvolvimento dos moldes, baseando-se o design do modelo, numa base de dados de moldes básicos, componentes normalizados e famílias ou blocos de moldes que representam o corpo humano. 
O molde é construído a partir de diagramas, na qual é utilizado princípios geométricos e estudos sobre antropometria, que consiste na ciência que levanta dados das diversas dimensões corporais. lida (2005, p. 97) afirma tal informação quando diz que a antropometria "trata das medidas físicas corporais, em termos de tamanho e proporções" que são bases para a concepção e aplicação dos princípios ergonômicos. Relata ainda que para que um produto possa ser considerado ergonomicamente qualificado ele deve passar por uma adequação antropométrica.

No desenvolvimento de novos projetos a antropometria é suporte na adequação do produto ao seu usuário sendo ferramenta para resolução de problemas de design. Esse processo de adaptação do produto ao usuário é um dos principais fatores de diferenciação e inovação no mercado. De tal modo, a antropometria tem a finalidade de ajudar o designer de moda a tomar consciência da importância das dimensões humanas no projeto e a estabelecer um vínculo entre antropometria e o projeto de vestuário.

Desta forma, os sistemas de modelagem utilizados atualmente detêm suas bases nas pesquisas realizadas sobre a proporcionalidade das medidas do corpo. Dados antropométricos adequados ao usuário e aplicados na etapa de concepção do produto reduzem o risco da indústria ter problemas referentes aos fatores relacionados a conforto, tamanho inadequado e usabilidade do produto (PANERO e ZELNIK, 2002). Por isso, o conhecimento da anatomia e o estudo das dimensões corporais são primordiais para o projeto, tendo em vista o desempenho de uso.

As proporções das medidas infantis são diferentes dos adultos, e segundo IIDA (2005, pg 98) "Homens e mulheres diferenciam-se entre si desde o nascimento. Os meninos são 0,6 cm mais compridos e 0,2 Kg mais pesados, em média". O crescimento até os 9 anos de idade caracterizam-se de formas semelhantes. Desta forma, cada empresa elabora uma tabela de medidas para a construção de seus moldes.

Entretanto se compararmos roupas fabricadas por empresas concorrentes, podemos encontrar diferenças grandes nas medidas de peças do mesmo tamanho, tanto no segmento infantil como no adulto, o que dificulta para o consumidor na hora da compra. Em busca de uma padronização das medidas infantis, a ABNT colocou em vigor a NBR 15800, sugerindo 24 medidas do corpo humano infanto-juvenil. Pois no Brasil muitas vezes o tamanho $\mathrm{P}$ de uma marca equivale ao tamanho $\mathrm{M}$ de outra.

Em nota na revista época publicada em 2011, foram analisados os extremos de medidas encontradas no setor infantil. Comparações apresentadas mostraram as diferenças entre as medidas menores, maiores, e as sugeridas do tamanho de número 4 pela ABNT (Figura 1). 


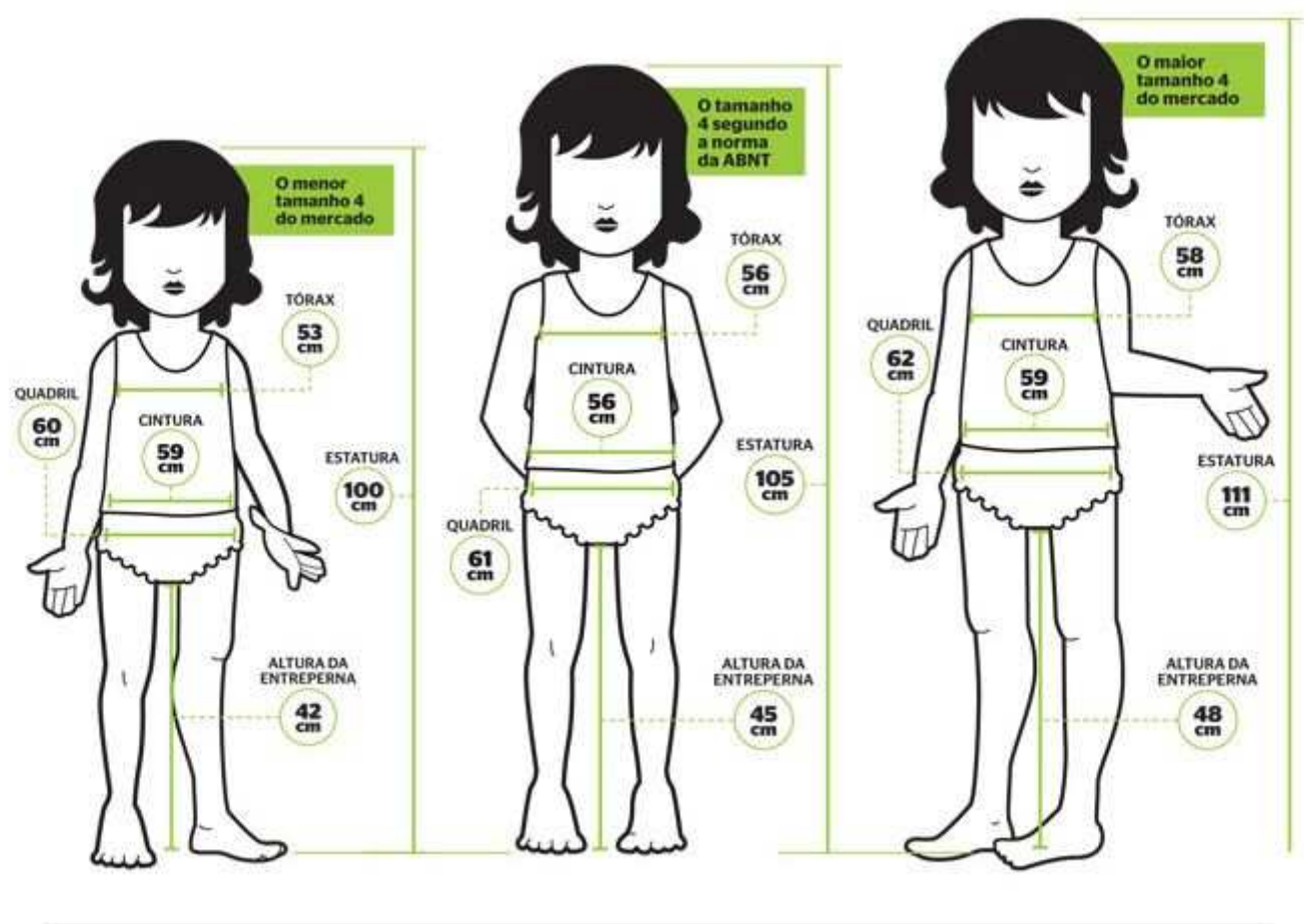

Figura 1 - Comparação de medidas entre o menor, ABNT e maior tamanho de número 4 encontradas no mercado de roupa infantil

Fonte: http://revistaepoca.globo.com

\subsection{Materiais e métodos}

No momento inicial da pesquisa a investigação foi realizada por meio de um levantamento bibliográfico, na qual buscaram-se dados quantitativos sobre a população e mercado infantil no Brasil. O levantamento de medidas do corpo foram consultadas a partir da ABNT - Associação Brasileira de normas técnicas. Norma em vigor a partir de 2009, NBR 15800 - Vestuário - Referenciais de medidas do corpo humano - Vestibilidade de roupas para bebê e infanto-Juvenil.

Após a coleta de dados bibliográficos, foram escolhidas 4 conjuntos de bebê fabricadas por empresas distintas, no tamanho G. Os mesmos eram compostos por calça e body, confeccionadas em malharia retilínea, as peças foram compradas em uma loja de varejo na cidade de Maringá-Pr.

As medidas tiradas da calça para comparação foram: Perímetro da cintura corresponde a letra $A$, comprimento da cintura ao tornozelo letra $D$, altura do entrepernas $\mathrm{C}$ e contorno do gancho da frente passando pelo cavalo até do gancho das costas corresponde a letra B (Figura 2). No body as medidas de comparação foram: Ombro a ombro corresponde a letra $E$, comprimento consolidado entre o extremo do ombro, cotovelo e pulso referente a letra $F$, e extensão entre a incisura jugular, passando pelo períneo, contornando a região glútea até a sétima vértebra cervical que corresponde a letra G (Figura 3). 

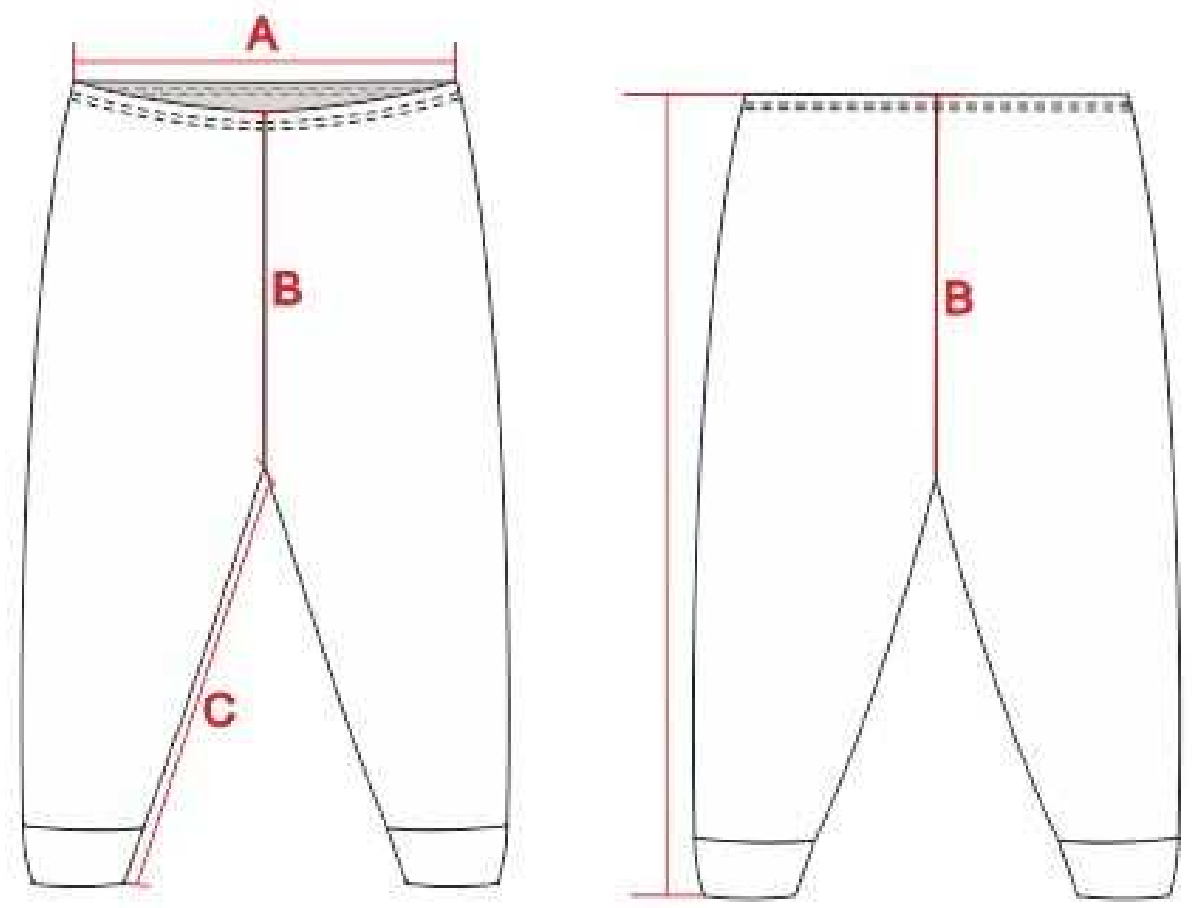

Figura 1 - Ilustração das medidas analisadas Fonte: Elaborado pelo autor
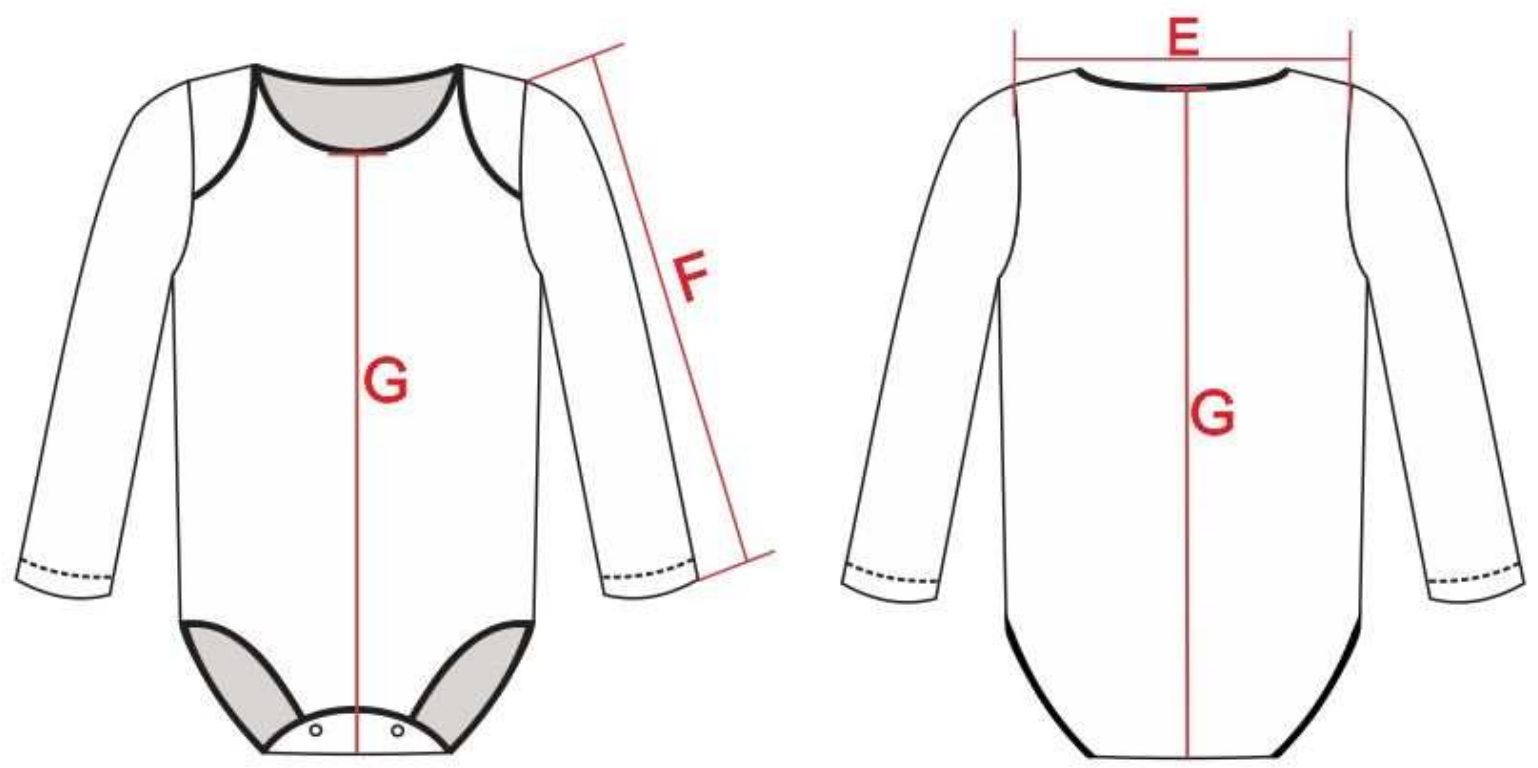

Figura 1 - Ilustração das medidas analisadas

Fonte: Elaborado pelo autor

\subsection{Resultados e discussão}


O conhecimento sobre antropometria estabelece uma direção para que as empresas criem suas tabelas de medidas, proporcionando segurança ao desenvolver as bases dos moldes de maneira padronizada. Em eventos de atualização dos profissionais de moda e de design são frequentes os questionamentos sobre as medidas antropométricas, especialmente em relação àquelas utilizadas no desenvolvimento de produtos. Com essa preocupação a ABNT sugeriu 24 medidas infantis na NBR 15500, indicado os tamanhos das medidas corporais. O estudo presente analisou algumas da principais medidas do tamanho $G$ de uma calça e um body, que se refere a idade de 9 meses. As informações das medidas analisadas da calça encontram-se no Quadro 1 e do body no quadro 2.

Quadro 1 - Comparação de medidas da calça de bebê tamanho G

\begin{tabular}{|l|l|l|l|l|l|l|}
\hline & Medidas em centímetros & $\begin{array}{l}\text { NBR } \\
\mathbf{1 5 8 0 0}\end{array}$ & Calça 1 & Calça 2 & Calça 3 & Calça 4 \\
\hline A & Perímetro total da cintura & 0,44 & 0,42 & 0,40 & 0,40 & 0,40 \\
\hline B & Contorno gancho frente e costas & 0,38 & 0,38 & 0,36 & 0,37 & 0,37 \\
\hline C & Entrepernas da cintura ao & 0,40 & 0,23 & 0,20 & 0,22 & 0,21 \\
\hline D & $\begin{array}{l}\text { Comprimento da } \\
\text { tornozelo }\end{array}$ & 0,38 & 0,37 & 0,37 \\
\hline
\end{tabular}

Fonte: Elaborado pelo autor, com base na pesquisa realizada.

Quadro 2 - Comparação de medidas do body de bebê tamanho $\mathbf{G}$

\begin{tabular}{|l|l|l|l|l|l|l|}
\hline & Medidas em centímetros & $\begin{array}{l}\text { NBR } \\
\mathbf{1 5 8 0 0}\end{array}$ & body 1 & body $\mathbf{2}$ & body 3 & body 4 \\
\hline E & Ombro a ombro & 0,21 & 0,21 & 0,18 & 0,20 & 0,20 \\
\hline F & $\begin{array}{l}\text { Comprimento consolidado entre o } \\
\text { extremo do ombro, cotovelo e pulso }\end{array}$ & 0,24 & 0,26 & 0,26 & 0,27 & 0,21 \\
\hline $\mathbf{G}$ & $\begin{array}{l}\text { Extensão entre a incisura jugular, } \\
\text { passando pelo períneo, } \\
\text { contornando a região glútea até a } \\
\text { sétima vértebra cervical }\end{array}$ & 0,78 & 0,78 & 0,79 & 0,69 \\
\hline
\end{tabular}

Fonte: Elaborado pelo autor, com base na pesquisa realizada.

\section{CONCLUSÃO}

Para o desenvolvimento de produtos do vestuário a indústria precisa de medidas antropométricas detalhadas. No entanto podemos perceber a partir das medidas averiguadas, que mesmo após a elaboração da NBR 15800, na busca em dar parâmetros para as empresas de roupas infantis tenham um padrão de medidas. De modo geral, os assuntos apresentados nesta pesquisa mostraram a importância sobre a antropometria, constatando que o sistema de medidas tem por objetivo a padronização dos tamanhos, e que pesquisas antropométricas têm contribuído para a definição das medidas do corpo. 
Entretanto a partir das medidas averiguadas, confirmam-se a falta de padronização das medidas infantis atualmente utilizadas nas indústrias. Nas peças analisadas e comparadas com NBR 15800 foi possível verificar que algumas medidas sofrem uma maior variação, como o comprimento consolidado entre o extremo do ombro, cotovelo e pulso do body, que a menor medida tem $21 \mathrm{~cm}$ e o maior $27 \mathrm{~cm}$, uma diferença de $6 \mathrm{~cm}$. Já na Extensão entre a incisura jugular, passando pelo períneo, contornando a região glútea até a sétima vértebra cervical encontramos uma diferença da menor entre a maior medida de $10 \mathrm{~cm}$. Na calça a maior diferença encontrada foi no entrepernas, $7 \mathrm{~cm}$ entre a medida maior e a menor.

Desta forma concluímos que as indústrias confeccionistas ainda precisam implantar a padronização em sua produção visando atingir qualidade do vestuário infantil, o que também irá facilitar para o consumidor na hora da compra.

\section{Agradecimentos}

Os autores deste trabalho agradecem as instituições que proporcionaram o seu desenvolvimento e ao apoio pela participação no 11 으 Congresso Brasileiro de Pesquisa e Desenvolvimento em Design- P\&D.

À UTFPR - Universidade Tecnológica Federal do Paraná, câmpus Apucarana. À PPGDesign UNESP - Universidade Estadual Paulista.

\section{REFERÊNCIAS}

Associação Brasileira de Normas Técnicas. NBR 15800 - Vestuário - Referenciais de medidas do corpo humano - Vestibilidade de roupas para bebê e infanto-Juvenil. Novembro, 2009.

ARIÉS, P. História Social da Criança e da Família. Rio de Janeiro: LTC, 1981.

DAUJOTAS, G. More Adults, Fewer Children: A Threat or an Opportunity for Toys?. London, 2011. Disponível em: <http://blog.euromonitor.com/2011/07/more-adultsfewer-children-a-threat-or-an-opportunity-for-toys-.html>. Acesso em: 23 Jul. 2013.

IIDA, I. Ergonomia: Projeto e Produção. São Paulo: editora Edgard Blucher, 2005.

ROSA, Stefania. Alfaiataria: Modelagem plana masculina. Brasília: Senac, 2012.

REVISTA ÉPOCA. A medida certa para seu corpo. São Paulo, 2011. Disponível em:<www.revistaepoca.globo.com/revista/epoca/0,„Epoca/0,,EMI204420-15201,00a+medida+certa+para+seu+corpo.html>. Acesso em: 27 Jul. 2013.

SPAINE, P.A.A. Modelagem Plana Indústrial do Vestuário: Diretrizes para a Indústria do vestuário ensino-aprendizado. Bauru, 2010. Dissertação (Mestrado em Design) Universidade Estadual Paulista.

www.jornaldehoje.com.br. Crescimento do mercado infantil ganha destaque no segmento têxtil. Natal-RN, 2013. Disponível em: $<w w w$.jornaldehoje.com.br/crescimento-do-mercado-infantil-ganha-destaque-nosegmento-textil/>. Acesso em: 25 Jul. 2013. 